\title{
Application of the Bionic Concept in Reducing the Complexity Noise and Drag of the Mega High-Speed Train Based on Computer Simulation Technologies
}

\author{
He-xuan Hu $\mathbb{D}^{1,2}{ }^{1,2}$ Bo Tang, ${ }^{2,3}$ and Ye Zhang $\mathbb{D}^{1}$ \\ ${ }^{1}$ College of Computer and Information, Hohai University, Nanjing 211100, China \\ ${ }^{2}$ Department of Electrical Engineering, Tibet Agricultural and Animal Husbandry College, Tibet 860000, China \\ ${ }^{3}$ College of Energy and Electrical Engineering, Hohai University, Nanjing 211100, China \\ Correspondence should be addressed to He-xuan Hu; hexuan_hu@hhu.edu.cn
}

Received 7 May 2018; Revised 4 July 2018; Accepted 15 July 2018; Published 1 August 2018

Academic Editor: Changzhi Wu

Copyright (c) $2018 \mathrm{He}$-xuan $\mathrm{Hu}$ et al. This is an open access article distributed under the Creative Commons Attribution License, which permits unrestricted use, distribution, and reproduction in any medium, provided the original work is properly cited.

\begin{abstract}
Regarding the continuous development of high-speed trains and the increase of running speeds, the aerodynamic design of highspeed trains has become significantly important, while reduction of drag and noise comprises a significant challenge in order to optimize aerodynamic design of high-speed trains. The design form factor of a high-speed train is highly influenced by aerodynamic aspects including aerodynamic drag, lift force, and noise. With the high-speed train as the object, the paper aims to take bionic concept as the entry point, selecting the hummingbird as the bionic prototype and extracting bionic elements to establish a bionic train model. Then, the finite volume method was used for numerical simulation and analysis of the aerodynamic performance and aerodynamic noise of the bionic high-speed train. Computational results prove that drag and noise of the bionic head type were lower than those of the original train; drag of the head train of the bionic model was reduced by $2.21 \%$ in comparison with the original model, while the whole-train drag was reduced by $3.53 \%$, indicating that drag reduction effects are available and implying that the bionic head type could reduce drag and noise. Noise sources of the bionic train are mainly located at positions with easy airflow separation and violent turbulence motion. Large turbulence energy is in bogie areas and mainly exists at the leeward side of the bogie area. Obviously, the bogie area is the major noise source of the train. Aerodynamic noise of the bionic train in far-field comprises a wide-frequency range. Noises were concentrated within $613 \mathrm{~Hz} 3150 \mathrm{~Hz}$. When the bionic high-speed train ran at $350 \mathrm{~km} / \mathrm{h}$, through comparative analysis of total noise levels at observed points of the high-speed train, it is found that this position with the maximum noise level was $25 \mathrm{~m}$ away from the head train nose tip, with the maximum value of $88.4 \mathrm{~dB}(\mathrm{~A})$. When the bionic train ran at $600 \mathrm{~km} / \mathrm{h}$, the maximum sound pressure level at the longitudinal point was $99.7 \mathrm{~dB}(\mathrm{~A})$ and the average noise level was $96.6 \mathrm{~dB}(\mathrm{~A})$. When the running speed increased from $350 \mathrm{~km} / \mathrm{h}$ to $600 \mathrm{~km} / \mathrm{h}$, the maximum noise level increased by $11.3 \mathrm{~dB}(\mathrm{~A})$ and the average noise level increased by $11.6 \mathrm{~dB}(\mathrm{~A})$. Computation results of aerodynamic noise at the point which is $7.5 \mathrm{~m}$ away from the rail center show that the maximum aerodynamic noise level existed at the first-end bogie of the head train, while the noise level was larger at the position closer to the ground.
\end{abstract}

\section{Introduction}

In some sense, high-speed trains are one of the many representatives of innovative power of a nation. For example, high-speed trains under Mount Fuji in Japan have become the calling card of Japanese Shinkansen [1]. 700 series trains with a unique shape have been called as "Platypus" and are widely known in the society. After that, Shinkansen head types adopted bionic elements of birds and fish. Heads of Germany ICE trains are shaped like spheroids and mainly adopt organic curves and faces. High-speed trains in France have tough and sharp shapes as well as bold coating, embodying romantic themes of France. In order to find design enlightenment and cater to people's desire for nature, a lot of fields have applied a lot of natural elements. High-speed trains have also started bionic modeling, while the most 
typical benefit is the outstanding aerodynamic performance [2]. Therefore, it has been tried to adopt the animals head form properties in designing the high-speed train heads [3] as they have shape characteristics which can be recognized quickly while their appearance is intimate and impressive. According to the evolution theory [4], in the evolution of animals, species development has been towards increasing speed and consuming less energy. Perfect body structures of animals have a better aerodynamic performance over artificial traffic tools. Animals which have perfect body structures perform quite well in aerodynamic performance, especially in aspects such as reduction of drag and energy, saving of energy consumption, reduction of emission, and environmental-friendly effects. Through discussion and research of bionic design theories, the paper makes beneficial supplementation for existing train shape design theories, summarizes excellent innovative design methods both at home and abroad, and further explores associations between head type bionic design of high-speed trains and their aerodynamic performance, expecting to provide reference for design of head types of high-speed trains.

Bionics is a discipline which has achieved very fast development in recent years [5]. Bionics is a comprehensive discipline which aims to research special structures, performance, signal control and feedback, energy conversion, and other aspects of organic creatures, apply them into a technical engineering system, improve existing technical engineering equipment, and create new technical engineering systems such as structural construction and automated equipment. To be brief, it is a science which imitates creatures. A lot of experts have conducted different researches about the application of bionic elements in engineering technologies such as animal bionics, plant bionics, human bionics, and microorganism.

Based on different bionic perspectives of high-speed trains, many scholars have conducted the following researches on the bionic design of engineering structures. As for the aircrafts, Combes and Daniel [6-8] experimented hawk moth wings, finding that aerodynamic force only brought tiny influences on passive elastic deformation of wings. As believed by Usherwood and Ellington [9], the liftdrag ratio of deformation wings of a traditional aircraft was only increased to a small range, but their effects in dynamic wing patting shall be reconsidered. Nguyen et al. [10] tested two artificial wings with shapes of horsefly and hawk moth, wherein the wing was rotated by the angle of $60^{\circ}$. Within the patting frequency of $6-12 \mathrm{~Hz}$, the optimum wing shape was found. Chen et al. [11] researched drag reduction effects during pigeon flying; quantified morphological characteristics and geometrical information of wing feather rear edge of the pigeon were quantified. Modeling was conducted to the bionic wing shape model, while its aerodynamic characteristics were analyzed. It is found that the bionic wing model can reduce air drag with the maximum reduction range of about $9.1 \%$. Based on a three-dimensional wing, Shi et al. [12] conducted waveform design of the front and rear edges and researched drag reduction mechanism of the waveform three-dimensional bionic wing structure with parameters such as flow field structure and boundary layers. Zhang et al. [13] conducted analog simulation of fluid dynamic features of bionic flapping wings based on fluent, finding that fluid dynamic force of bionic flapping wings showed linear characteristics under small angles of attack, but embodied nonlinear changing trends under large angles of attack. Based on microcosmic rough surface waxiness of the nanoscale of the lotus leaf surface, Wang et al. [14] introduced principles, manufacture methods, and research statuses of bionic iceproof materials. Tong et al. [15, 16] and Jin et al. [17] researched flapping of insects such as dragonflies and yellow jackets and also conducted flow field researches of C-type and S-type starting vorticity and so forth of fish. With regard to automobiles, Bouchard et al. [18] believed that bionic design appears at two main stages of specific automobile design course, including the external inspiration source which associates "regular" and "irregular" activities. Tian et al. [19], enlightened by fish that uses center fins to generate disturbance to fluids so as to enhance motion stability, added disturbance plates similar with center fins in functions on the car tail part; aiming at the drag increase and on this basis, a ribbed bionic functional surface was added on the surface of the automobile and the automobile rear window. Numerical computation results show that adhesive force of the rear wheel was enhanced; handling stability of the car was enhanced; tail airflows were teased effectively; airflow separation was delayed; the drag decrease rate reached $4.938 \%$. Song et al. [20] applied the bionic pit slot technical structure on the automobile surface to control the boundary layer to realize scattering decrease, so that loss of turbulent kinetic energy can be reduced. As for trains, Lee and Kim [21] conducted optimization analysis of nose tip of a train and obtained a nose tip shape with better aerodynamic performance. Hargroves and Smith [22] introduced streamlines of Japanese 500 series Shinkansen trains for bionic design of kingfisher bills. To reduce aerodynamic drag of high-speed trains, Du et al. [23] took the shark surface as the bionic object, established the geometric profile of a bionic nonsmooth groove, and researched drag reduction effects of the bionic nonsmooth grooves, finding that the drag reduction rate could reach over $6 \%$. To reduce aerodynamic noise of high-speed trains, Wang et al. [24, 25] designed the Koch snowflake surface texture and the rhombus surface texture on the carriage of a train, finding that noise was reduced obviously. In combination with the bionic shape, $\mathrm{Xu}$ et al. $[26,27]$ looked into industrial design of high-speed trains from man-machine engineering and emotionalized design. Yi et al. [28] analyzed bionic trains of Malaysian high-speed trains inspired from Malaysian tigers and summarized characteristics of successful design of form bionics. Wang W. and Wang Z. [29] analyzed practice and appearance design methods of Korean high-speed rails from 4 aspects such as train aerodynamics, symbol design, fusion and coexistence of national cultures, and bionic design. Shi et al. [12] applied the owl wing front-edge sawtooth structure in cylindrical rod surfaces for bionic design, researched its noise reduction performance, and explored noise reduction effects brought by the application of the surface bionic structure in high-speed train pantographs. Qi [1] selected a lot of bionic prototypes, conducted three-dimensional transformation of train head 
types, applied Chinese sturgeon elements in train shape design, and computed the aerodynamic drag coefficient of it under the running speed of $350 \mathrm{~km} / \mathrm{h}$, but failed to analyze the reasons for drag decrease.

Based on theories and methods of CFD (computational fluid dynamics), the paper applies the computational fluid software FLUENT for the numerical simulation. Main research contents are as follows: animals with high speeds in the nature were extracted; feature control lines were extracted; design requirements such as high-speed train limits were considered; CAD software was used to simulate a high-speed train bionic geometric model. Based on aerodynamic theories of vehicles [30], the existing high-speed train $\mathrm{CRH}$ was taken as the reference object to set up an aerodynamic computation model of the high-speed train bionic model. Based on Lighthill acoustic analog theories, the aerodynamic noise model of bionic model was established. The FW-H equation [31] was used to solve propagation characteristics of acoustic fields. Based on drag characteristics, lift force characteristics, aerodynamic pressure distribution, aerodynamic noise characteristics, and other aspects of trains, bionic elements of the train bionic model were weakened; engineering improvements were realized, so engineering requirements for shape technologies, running, and so forth could be reached.

\section{Mathematical Model of High-Speed Trains Based on the Bionic Concept}

Mathematical method of the aerodynamic performance of high-speed trains involves three-dimensional, incompressible, viscous, and non-fixed-length turbulence flow fields as well as the controllable differential equation with the form of Reynolds-averaged Navier-Stokes equations (RANS) [32, 33]. In other words, the standard $k-\varepsilon$ model is as follows.

(i) Equation of continuity:

$$
\frac{d \rho}{d t}+\frac{\partial(\rho u)}{\partial x}+\frac{\partial(\rho v)}{\partial y}+\frac{\partial(\rho w)}{\partial z}=0
$$

(ii) Momentum conservation equation:

$$
\begin{gathered}
\frac{\partial(\rho u)}{\partial t}+\operatorname{div}(\rho u \vec{u})=\operatorname{div}(\mu \cdot \operatorname{grad} u)-\frac{\partial p}{\partial x}+S_{M x}, \\
\frac{\partial(\rho v)}{\partial t}+\operatorname{div}(\rho v \vec{v})=\operatorname{div}(\mu \cdot \operatorname{grad} v)-\frac{\partial p}{\partial y}+S_{M y}, \\
\frac{\partial(\rho w)}{\partial t}+\operatorname{div}(\rho w \vec{w})=\operatorname{div}(\mu \cdot \operatorname{grad} w)-\frac{\partial p}{\partial z}+S_{M z} .
\end{gathered}
$$

(iii) Energy conservation equation:

$$
\frac{\partial(\rho i)}{\partial t}+\operatorname{div}(\rho i \bar{u})=\operatorname{div}\left[\left(\frac{\kappa}{c_{\mathrm{p}}}+\frac{\mu_{\mathrm{t}}}{\sigma_{T}}\right) \operatorname{grad} T\right]+\Phi .
$$

(iv) Turbulence energy equation:

$$
\frac{\partial(\rho k)}{\partial t}+\operatorname{div}(\rho k \bar{u})=\operatorname{div}\left[\left(\mu+\frac{\mu_{\mathrm{t}}}{\sigma_{k}}\right) \operatorname{grad} k\right]-\rho \varepsilon+\mu_{\mathrm{t}} P_{G} .
$$

(v) Turbulence energy dissipation rate equation:

$$
\begin{aligned}
\frac{\partial(\rho \varepsilon)}{\partial t}+\operatorname{div}(\rho \varepsilon \bar{u})= & \operatorname{div}\left[\left(\mu+\frac{\mu_{\mathrm{t}}}{\sigma_{\varepsilon}}\right) \operatorname{grad} \varepsilon\right] \\
& -\rho C_{2} \frac{\varepsilon^{2}}{k}+\mu_{\mathrm{t}} C_{1} \frac{\varepsilon}{k} P_{G}, \\
\mu_{t}= & \rho C_{\mu} \frac{k^{2}}{\varepsilon}, \\
P_{G}=2 & {\left[\left(\frac{\partial u}{\partial x}\right)^{2}+\left(\frac{\partial v}{\partial y}\right)^{2}+\left(\frac{\partial w}{\partial z}\right)^{2}\right] } \\
& +\left(\frac{\partial u}{\partial y}+\frac{\partial v}{\partial x}\right)^{2}+\left(\frac{\partial u}{\partial z}+\frac{\partial w}{\partial x}\right)^{2} \\
& +\left(\frac{\partial v}{\partial z}+\frac{\partial w}{\partial y}\right)^{2}+\lambda(\operatorname{div} \vec{u}),
\end{aligned}
$$

where $u, v$, and $w$ are components of flow rates in coordinate directions of $x, y$, and $z$; $\rho$ is the fluid volume density, constant is used as for the incompressible equation; $\mu$ is dynamic viscosity density of fluid; $\mu_{\mathrm{t}}$ is the turbulence viscosity; $k$ is the turbulence kinetic energy; $\varepsilon$ is the dissipation rate of turbulence kinetic energy; $T$ is the fluid temperature; $\kappa$ the is thermal conductivity of air; $c_{\mathrm{p}}$ is specific heat of air mass at constant pressure; $C_{1}, C_{2}, C_{\mu}, \sigma_{k}$, and $\sigma_{\varepsilon}$ are constant empirical values, which are 1.44, 1.92, $0.09,1.0$, and 1.3, respectively; $\Phi$ is the dissipation function; and $S_{M x}, S_{M y}$, and $S_{M z}$ are source items of momentum equations in directions of $x, y$, and $z$.

$$
\begin{aligned}
S_{M x}= & {\left[\frac{\partial}{\partial x}\left(\mu \frac{\partial u}{\partial x}\right)+\frac{\partial}{\partial y}\left(\mu \frac{\partial v}{\partial x}\right)+\frac{\partial}{\partial z}\left(\mu \frac{\partial w}{\partial x}\right)\right] } \\
& +\frac{\partial}{\partial x}(\lambda \operatorname{div} \vec{u}), \\
S_{M y}= & {\left[\frac{\partial}{\partial x}\left(\mu \frac{\partial u}{\partial y}\right)+\frac{\partial}{\partial y}\left(\mu \frac{\partial v}{\partial y}\right)+\frac{\partial}{\partial z}\left(\mu \frac{\partial w}{\partial y}\right)\right] } \\
& +\frac{\partial}{\partial y}(\lambda \operatorname{div} \vec{u}), \\
S_{M z}= & {\left[\frac{\partial}{\partial x}\left(\mu \frac{\partial u}{\partial z}\right)+\frac{\partial}{\partial y}\left(\mu \frac{\partial v}{\partial z}\right)+\frac{\partial}{\partial z}\left(\mu \frac{\partial w}{\partial z}\right)\right] } \\
& +\frac{\partial}{\partial z}(\lambda \operatorname{div} \vec{u}) .
\end{aligned}
$$

In the RNG $k-\varepsilon$ model $[34,35]$ (renormalization group, RNG), influences of small scales are embodied by the viscosity item after large-scale motion and amendment, so smallscale motion can be systematically removed from the control 


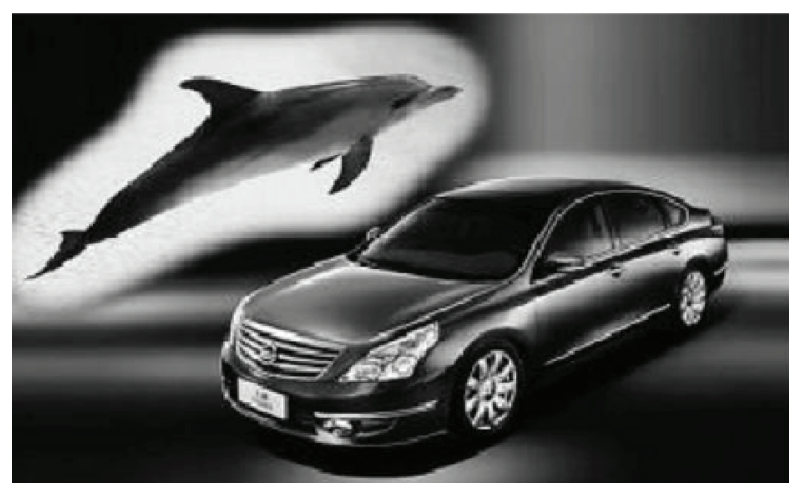

(a) Engineering bionics of dolphin [36]

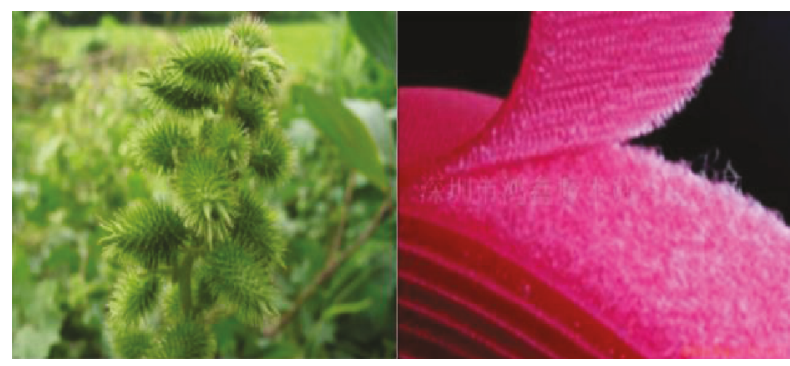

(b) Engineering bionics of xanthium plant [36]

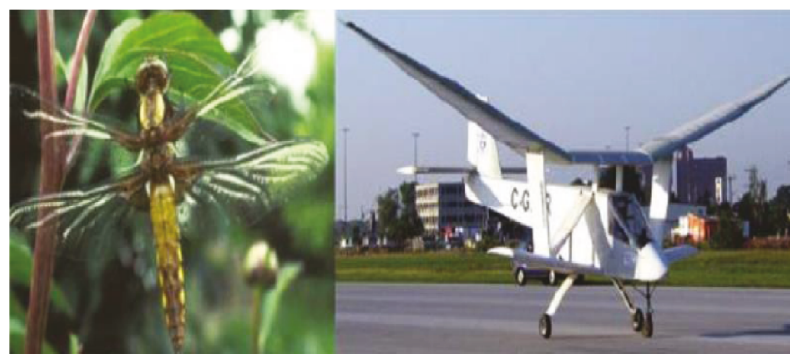

(c) Engineering bionics of dragonfly wings [37]

FIgURE 1: Real examples of engineering bionic design.

equation. Through amendment of the turbulence viscosity, rotation and rotation flowing in average flowing are taken into account. The time-average strain rate in main streams can be reflected. Obviously, the RNG $k-\varepsilon$ model can better deal with flowing with high strain rates and large flow line bending degrees. In comparison with the standard $k-\varepsilon$ model, it can get converged more easily in aerodynamic performance computation of high-speed trains. Hence, it is widely applied in engineering practice. Therefore, the RNG $k-\varepsilon$ turbulence model is selected in computing aerodynamic performance of the train.

\section{Numerical Model of High-Speed Trains Based on the Bionic Concept}

3.1. Bionic Design Science. Various creatures in the nature have peculiar skills, which attract human to explore their secrets. Based on observation, thinking as well as rich imagination, and creativity, people use various methods and technologies to imitate and upgrade special skills and advantages of creatures, do creative work, and create more rational and outstanding tools. Bionic design science takes some elements
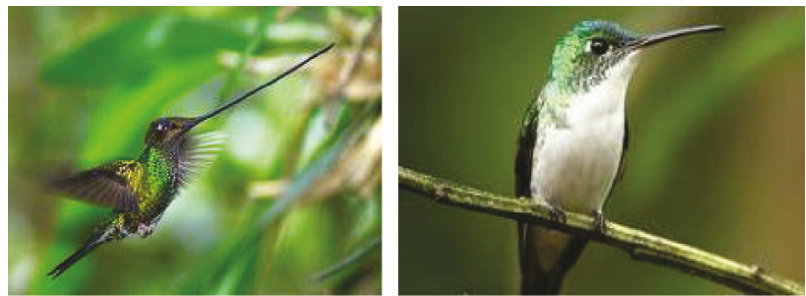

Figure 2: Hummingbirds as the selected excellent bionic prototypes.

or individuals existing in the nature as research objects, applies these elements during design in a selective and purposeful manner, makes combination with engineering application, and provides diversified new methods for engineering design. Research types of bionic design include form bionics, function bionics, color bionics, and structure bionics.

As shown in Figure 1(a), when optimization of automobile shape and intercavity interaction needs to be considered during engineering design, analysis and research can be conducted to some creative structures which have weak interactions with fluids, so a low-drag profile can be obtained. In addition, bionics can be conducted with some structures of objects. Figure 1(b) shows the design of a nylon hook and loop fastener realized by interactions between plants and external environment. As shown in Figure 1(c), engineering application of wings which imitate dragonfly wings was realized. Research results show that wings imitating dragonfly wings have advantages such as high structural strength, light mass, and good aerodynamic characteristics, which can help to enhance flight performance of planes significantly.

\subsection{Selection of Excellent Bionic Prototypes. High-speed train} is considered as a form of transformation vehicles with a high running speed. During its head type design, animals with high speeds in the nature will be associated. From the perspective of aerodynamics, birds flying in air and fish in water have realized survival of the fittest during hundreds of millions of years and take a place in the biologic chain because of their nice head streamline. There are a lot of excellent species. Due to the limit of time and vigor, the paper selects a representative animal for further research and analysis.

Among all the animals, hummingbird (as shown in Figure 2) has the nice shape and magnificent colors. With the smallest volume, it is light, rapid, and agile. Magnificent feather flickers with the gloss of metal, as bright as diamond. Nectar is its favorite. The long and thin beak extends deep into a flower, but will not bring any harm to the flower, indicating that hummingbird has very good flying performance and a smooth beak shape. They are distributed in the hottest areas of America and behave actively between two tropics, just like the followers of sun. In American myths, it is deemed as the god of sun, which brings kindling to the world.

3.3. Three-Dimensional Transformation of Bionic Prototype and Referential Train Type. In order to study advantages and mechanisms of bionic design in drag reduction, the $\mathrm{CRH} 3$ train was taken as a referential model (see Figure 3). 


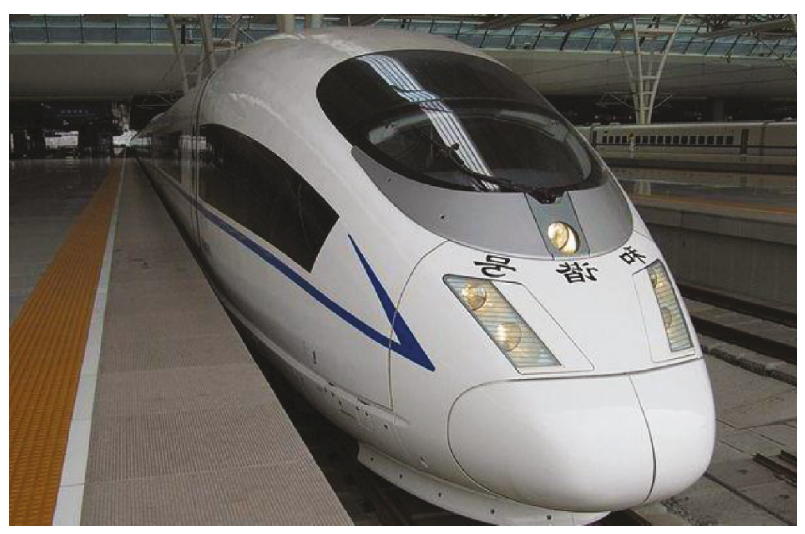

FIGURE 3: The referential CRH3 high-speed train.

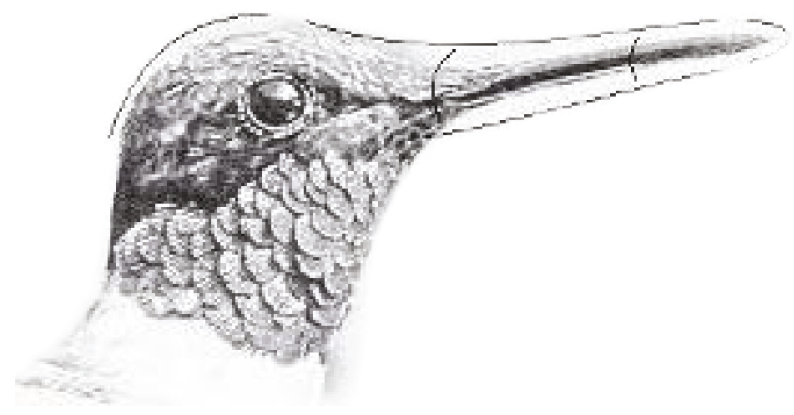

Figure 4: Streamline head type of the hummingbird type.

Three-dimensional construction of form of the hummingbird was conducted to ensure normalizing. In order to keep form characteristics of the animal to the hilt, structures such as cab window, diversion trench, top and bottom structures of the train, and intertrain joints are not considered temporarily. In this way, construction made by the bionic prototype to aerodynamic reduction in drag and noise can be researched more purely.

From the complicated three-dimensional structure, characteristic lines which have the simplest structure and contain the most form connotations are extracted. Different species have different shapes, so their characteristic lines are different. Head feature lines of the hummingbird are used to design streamline parts of the train head, so the form bionic sense of train head can be embodied. With stronger bionic elements, characteristic lines can generate stronger bionic sense. At first, minor characteristics are neglected through observation of main appearance characteristics of the animal. Secondly, main appearance characteristics extracted at the first step are simplified in combination with form structure characteristics of the train, such as longitudinal control line of head part, horizontal control line of head part, and cross-section outline line of the train body, while simplified results are applied to form design of streamline parts of the train head part, as shown in Figure 4.

Head type of hummingbirds was taken as the research object. Original head type for hummingbird bionic design was established, as shown in Figure 5. It was simplified to be similar with $\mathrm{CRH}$ high-speed train. Structural control lines and faces were optimized for mesh division and

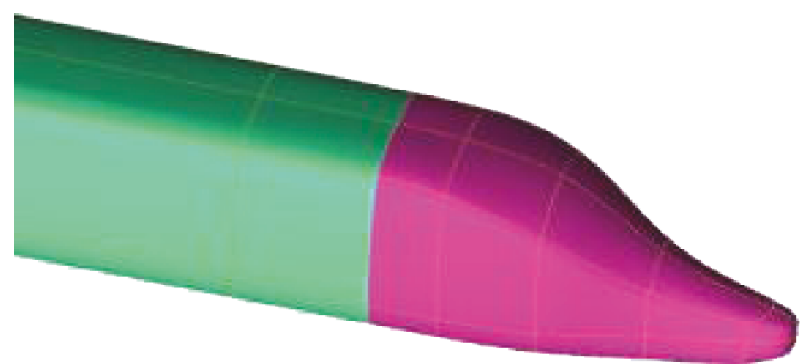

FIgURE 5: Bionic head type of high-speed trains based on hummingbirds.

computation. Main reference indexes include crosssectional area and streamline length. After simplification, the mid train is $25 \mathrm{~m}$ long and the tail train is $25 \mathrm{~m}$ long. Three-train marshalling was adopted. The whole train is $75 \mathrm{~m}$ long, $3.64 \mathrm{~m}$ high, and $3.26 \mathrm{~m}$ wide, wherein the streamline length was about $7.45 \mathrm{~m}$.

\subsection{Engineering Application of Bionic Head Type.} Appearance of the hummingbird bionic head type is not flat. Aerodynamic pressures are distributed in a greatly uneven manner. Obvious areas of positive pressures and negative pressures appear. It bears huge positive and negative pressures, which may bring adverse influences to intensity and aerodynamic performance of trains. Hence, subsequent researches will conduct engineering improvements of streamline parts.

Engineering improvements of the bionic head types mainly focus on two aspects: streamline shape and streamline length size. Head elements of different animals have different characteristics. It is necessary to discover different bionic elements, so as to obtain application rules of bionic elements in the design of the high-speed train head shape.

A lot of shape elements of the animal are kept during initial design of bionic design. In engineering, the streamline is not applicable, while shape technologies are difficult. In order to satisfy requirements for engineering and manufacture technologies, engineering of the speed level $350 \mathrm{~km} / \mathrm{h}$ was conducted to the bionic design train. Length, width, and height of the streamline part can refer to the CRH3 highspeed train. Bionic elements were kept as much as possible. The unsmooth degrees were amended, and its aerodynamic performance was researched. During actual running, influences brought by bogies to flow fields during train running can be neglected. Bogie areas can be considered during engineering, so practical situations can be approached. The engineering-oriented application model is shown in Figure 6.

\subsection{Numerical Solution Domain of Bionic Head Type in} Engineering Application. Computational domain of the bionic train with the bionic head type is shown in Figure 7. The length $L=75 \mathrm{~m}$ was taken as the standard. Hence, the computational domain is $4 L$ long, $L$ wide, and $0.5 L$ high. The distance between head train nose tip and the inflowing entrance is $L$. The distance between the tail train nose tip and the outflow exit is $2 L$. The distance between the train and the track ground is $0.3 \mathrm{~m}$. The front cross section $\mathrm{ABCD}$ 


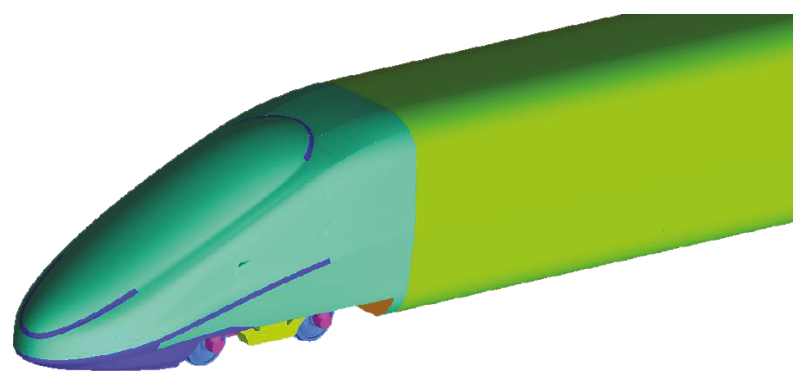

Figure 6: Engineering application head type of the hummingbird bionic design.

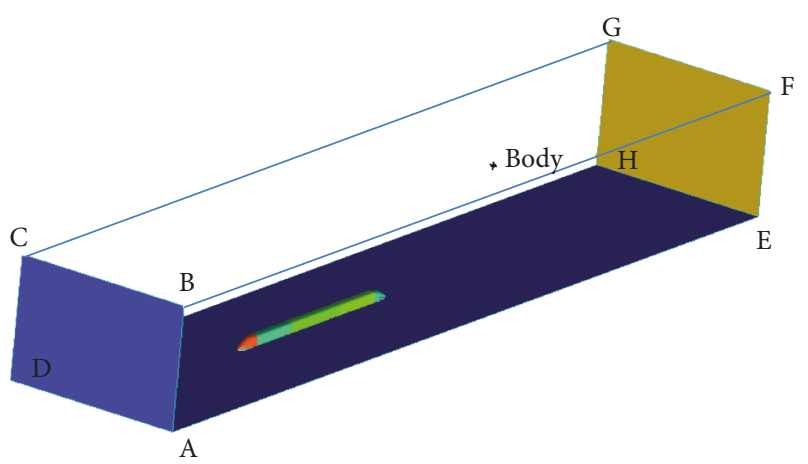

FIGURE 7: Aerodynamic noise computation domain of high-speed trains.

of the high-speed train was the entrance boundary and was set as the speed entrance condition, wherein the speed was $350 \mathrm{~km} / \mathrm{h}(97.2222 \mathrm{~m} / \mathrm{s})$ during the numerical computation. The rear cross section EFGH of the tail train of the highspeed train was the exit boundary and set as the pressure condition with the size of one standard atmospheric pressure. Cross section BFGC right above the high-speed train, the left cross section CGHD, and the right cross section AEFB were set as symmetric boundary conditions. Surface of the bionic train was set as the fixed boundary, belonging to the no-slippage wall face boundary condition. To simulate ground effects, the ground AEHD was set as the slippage ground, wherein its slippage speed was equal to the train running speed.

The tool ICEM CFD was used to divide meshes. Meshes with maximum outfield size of $1500 \mathrm{~mm}$, the maximum mesh of $60 \mathrm{~mm}$ on the train surface, and the maximum mesh of $30 \mathrm{~mm}$ on the bogie surface as well as other nonstructural meshes were extracted. Triangular meshes were adopted on the train body and bogie surface. Sizes of three-dimensional meshes were amplified according to proportional factors. Hexahedral meshes were adopted at positions far from the train body, and pentahedron pyramid meshes were adopted at transition parts from the tetrahedral meshes to hexahedral meshes. Local mesh densifying was conducted at parts with large changes of surface curvature at the streamline head type.

In order to eliminate influences of mesh density on computational results, three sets of meshes were selected for independence tests. Computation results of three sets of meshes
TABLE 1: Computation results of three sets of meshes.

\begin{tabular}{lccc}
\hline Mesh & $\begin{array}{c}\text { Quantity of meshes } \\
(1 \text { million })\end{array}$ & $\begin{array}{c}\text { Drag coefficient } \\
C_{\mathrm{d}} \text { of whole train }\end{array}$ & $\begin{array}{c}\text { Lift force } \\
\text { coefficient of } \\
\text { tail train } C_{1}\end{array}$ \\
\hline 1 & 27.78 & 0.1792 & 0.0359 \\
2 & 33.12 & 0.1866 & 0.0382 \\
3 & 36.82 & 0.1856 & 0.0373 \\
\hline
\end{tabular}

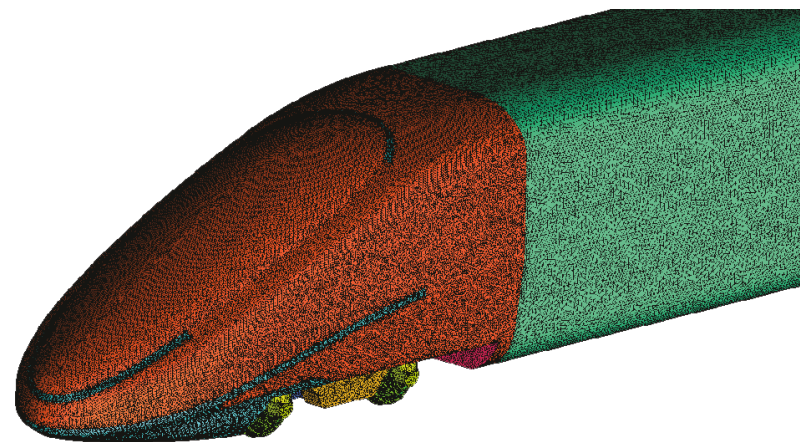

Figure 8: Meshes of head train of high-speed trains.

are shown in Table 1. Definitions of drag coefficient $C_{d}$ and lift force coefficient $C_{1}$ are

$$
\begin{aligned}
& C_{\mathrm{d}}=\frac{F_{\mathrm{d}}}{1 / 2 \rho v^{2} S}, \\
& C_{\mathrm{l}}=\frac{F_{\mathrm{l}}}{1 / 2 \rho v^{2} S},
\end{aligned}
$$

where $F_{\mathrm{d}}$ and $F_{1}$ denote aerodynamic drag and lift force borne by the high-speed train, $\rho$ denotes air density, $v$ denotes the running speed of the high-speed train, and $S$ denotes the maximum cross-sectional area of the highspeed train.

It is shown in Table 1: in comparison with the first set of meshes, the computed drag coefficient variation rate of the second set of meshes was $0.44 \%$, while the variation rate of lift force of the tail train was $3.73 \%$; in comparison with the second set of meshes, the computed drag coefficient variation rate of the third set of meshes was $0.12 \%$, while the variation rate of the lift force coefficient of the tail train was $0.78 \%$. In comparison with the second set of meshes, variation rate of computation results of the third set of meshes, as compared with the second set of meshes, was within $1 \%$. Hence, the size of the second set of meshes was finally applied in mesh division. Surface meshes of streamline areas of the head train are shown in Figure 8. Total number of corresponding meshes was about 33.12 million.

\section{Aerodynamic Performance Analysis of High- Speed Trains Based on the Bionic Concept}

4.1. Flow Field Characteristics of Bionic Trains. Noise source of the bionic train is the dipole noise. The dipole sound source on the train surface depends on pulsation pressure 


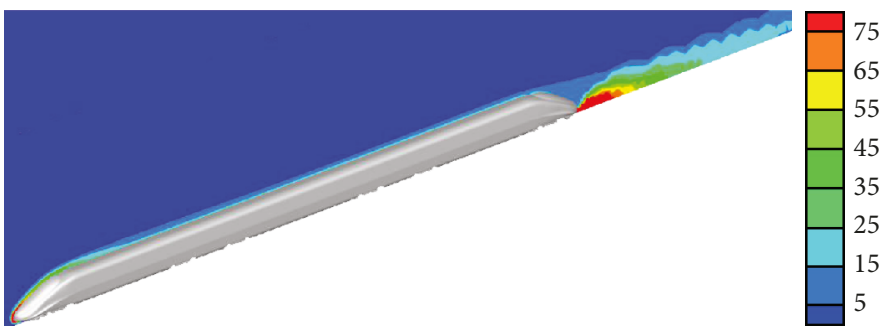

(a) Whole train

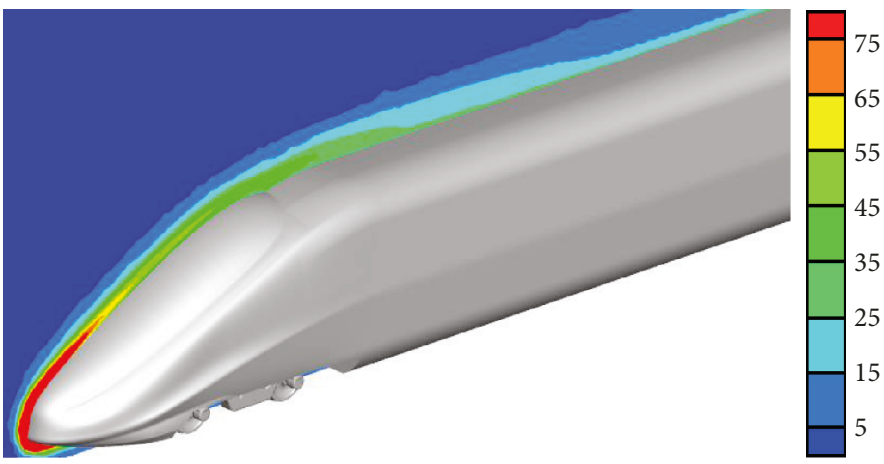

(b) Head train

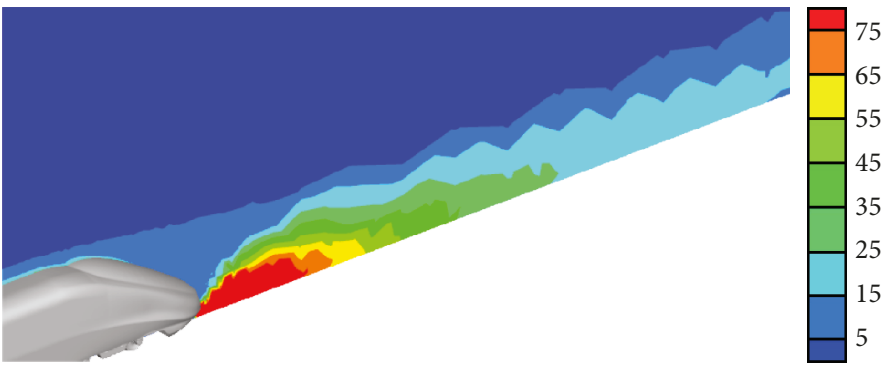

(c) Tail train

FIgURE 9: Distribution of turbulence kinetic energy around high-speed trains.

of the train surface. In other words, the size of the pulsation pressure on the train surface can reflect far-field noise radiation on the sound production face. According to three control equations of flow fields, turbulence energy equation, and turbulence dissipation rate equation, it is found that as for the size of the pulsation pressure on the train body surface, the turbulence energy $k$ can be used to assess distribution characteristics of train surface noise. Expression of the turbulence energy $k$ is $k=1 / 2\left({\overline{u^{\prime}}}^{2}+{\overline{v^{\prime}}}^{2}+{\overline{w^{\prime}}}^{2}\right)$.

Figure 9 shows distribution contours of surface turbulence energy of the whole train and the head. Figure 10 shows turbulence energy distribution contours on the head train surface. It is shown in Figure 9 that high turbulence energy was at the head nose tip and the rear area of the tail nose tip. Fluid separation and aggregation took place alternately. Hence, it is obvious that the head is the major noise source of the bionic train. It is shown in Figure 10 that turbulence energy also existed in bogie areas and mainly existed at leeward sides of the bogie areas. Hence, we can find that the bogie area is also the major noise source of the bionic train. Therefore, sound source areas of the high-speed train existed at positions with easy airflow separation and violent turbulence motion.
Figure 11 shows the pressure contour of the bionic train surface running at speed of $350 \mathrm{~km} / \mathrm{h}$. It is shown in Figure 11(b) that the pressure on the nose tip of the head train was the maximum, with the size of $5669 \mathrm{~Pa}$. The maximum negative pressure was located at the pilot, with the size of $10,636 \mathrm{~Pa}$. The speed at the stagnation point of the head train nose tip was 0 , and airflows got diverged at the head nose tip, so the maximum positive pressure appeared at the head nose tip. Due to flow choking at the windward side of the head train pilot, airflow separation appeared at the leeward side of the head train pilot and airflows quickly flow into the bogie area, so the maximum negative pressure appeared at the leeward side of the head train pilot. It is shown in Figure 11(c) that the pressure on the cab window of the tail train was the maximum, with the size of $2146 \mathrm{~Pa}$, which was attributed to the structure at the tail train window. The maximum negative pressure was located at the skirt board of the tail train bogie, with the size of $6900 \mathrm{~Pa}$.

4.2. Basic Aerodynamic Characteristics of Bionic Trains. Figure 12 shows the aerodynamic drag distribution contour of the bionic model, wherein the bionic high-speed train ran at $350 \mathrm{~km} / \mathrm{h}$. It is shown in Figure 12 that the sequence 


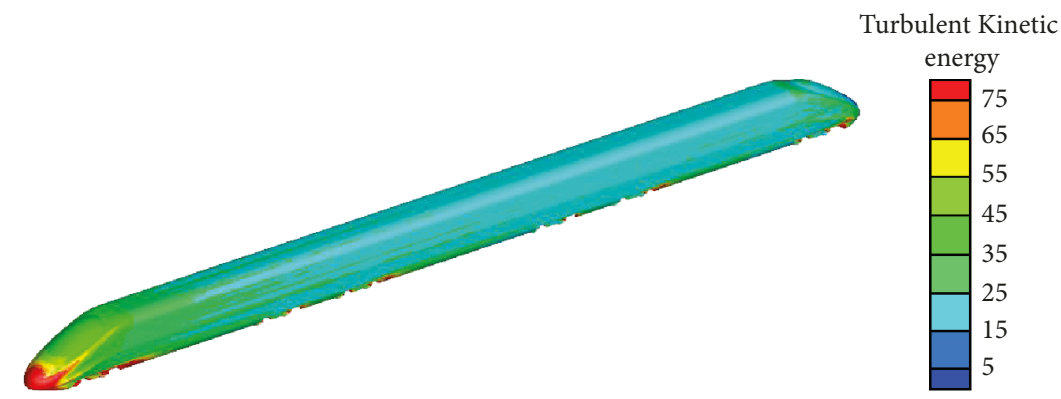

(a) Whole train

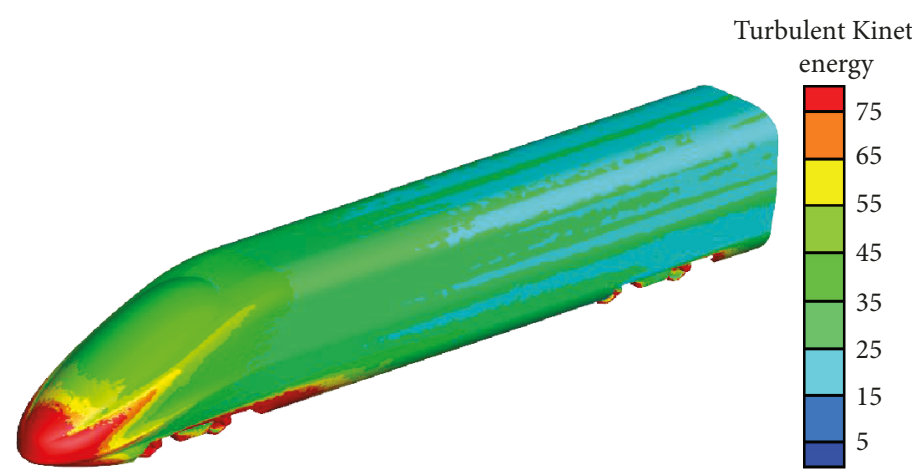

(b) Head train

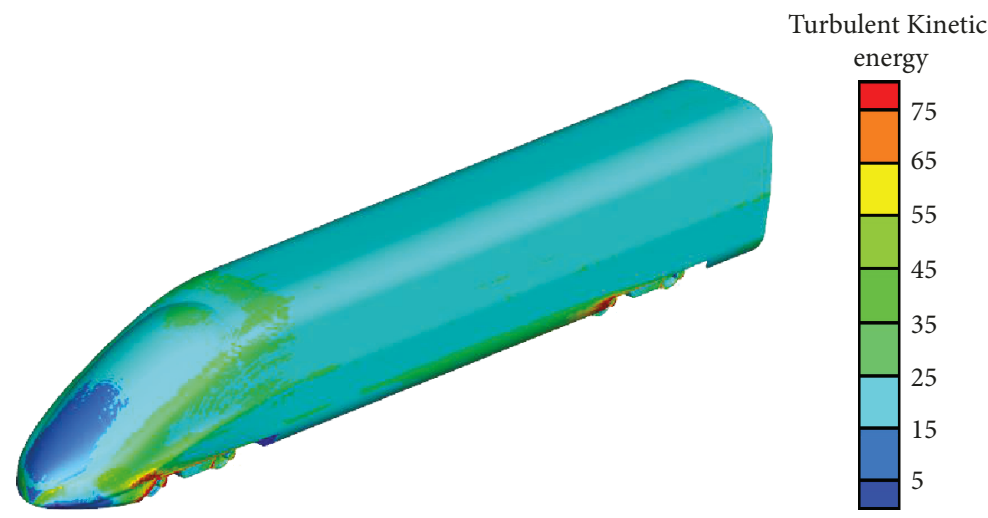

(c) Tail train

FIGURE 10: Distribution of turbulence kinetic energy of the bionic train body.

of the pressure difference of each train body (from large to small) is tail train, head train, and mid train; the sequence of the pressure difference drag of each train body (from large to small) is tail train, head train, and mid train, with values of $4821 \mathrm{~N}, 3637 \mathrm{~N}$, and $931 \mathrm{~N}$, respectively; the sequence of viscosity drag of each train body (from large to small) is head train, mid train, and tail train with values of $3095 \mathrm{~N}, 2457 \mathrm{~N}$, and $2138 \mathrm{~N}$, respectively; the drag of each train body (from large to small) is tail train, head train, and mid train, with values of $6960 \mathrm{~N}, 6733 \mathrm{~N}$, and $3389 \mathrm{~N}$, respectively; with drag of the bogie was considered, the sequence of total drag of each train body obtained (from large to small) is head train, tail train, and mid train, with values of $11,282 \mathrm{~N}, 8353 \mathrm{~N}$, and $5439 \mathrm{~N}$, respectively.

Meanwhile, basic aerodynamic coefficients were computed. Using (7) and (8), the drag coefficients of the head train, mid train, and tail train were $0.19,0.09$, and 0.15 , respectively; the lift force coefficients of the head train, mid train, and tail train were $-0.10,0.01$, and 0.17 , respectively. Obviously, the head train bore downward lift force; the tail train bore upward lift force; the mid train nearly bore no lift force.

Meanwhile, through comparison of aerodynamic drag of the CRH3 high-speed train, we can find that, as for the bionic train mode in the paper, the head train drag was reduced by $2.21 \%$; drag force of the whole train was reduced by $3.53 \%$. Drag reduction effects were obvious.

\section{Analysis of Aerodynamic Noise of High-Speed Train Based on Bionic Design}

5.1. Arrangement of Observed Points. Noise of high-speed trains along lines is one of the high-speed train noise problems attracting most attention from people. Far-field lateral 


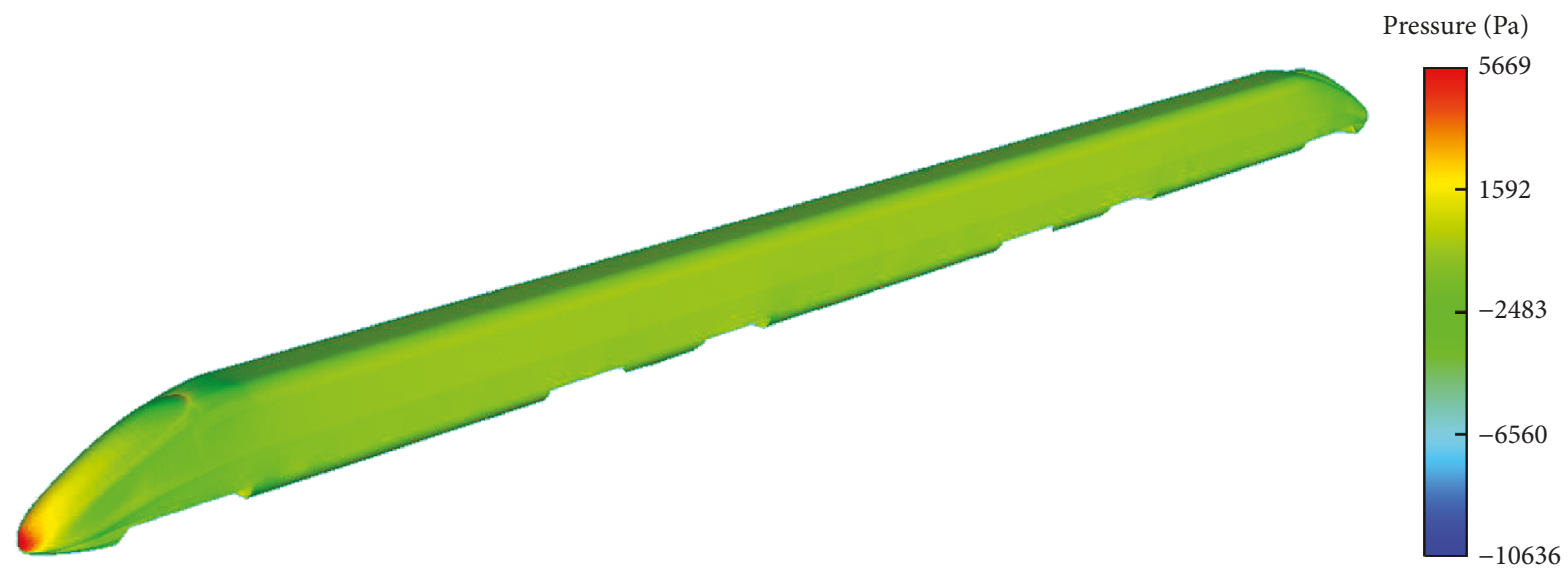

(a) Whole train

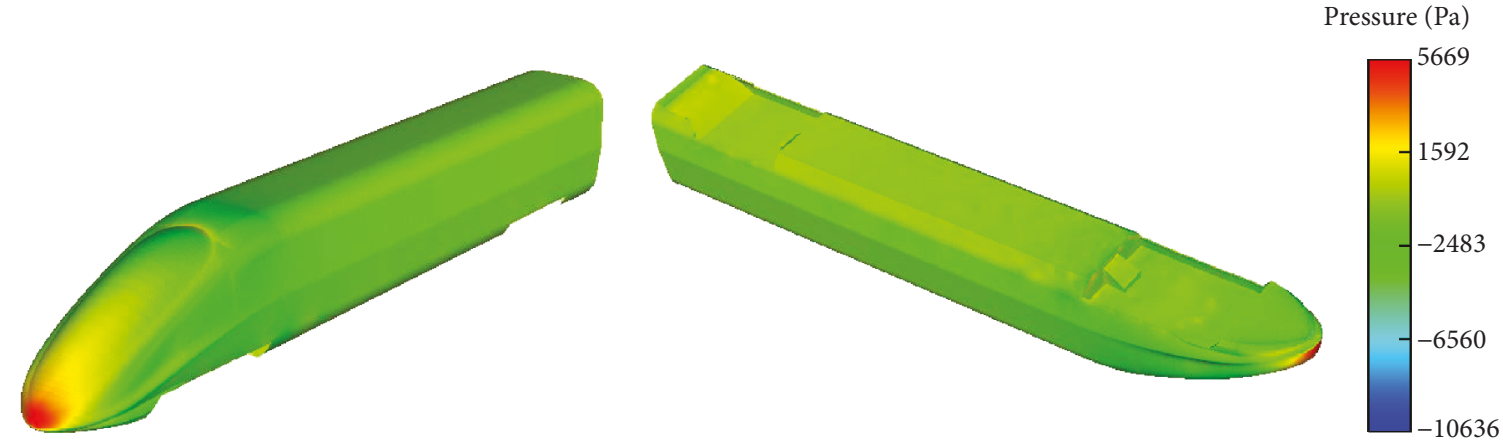

(b) Head train
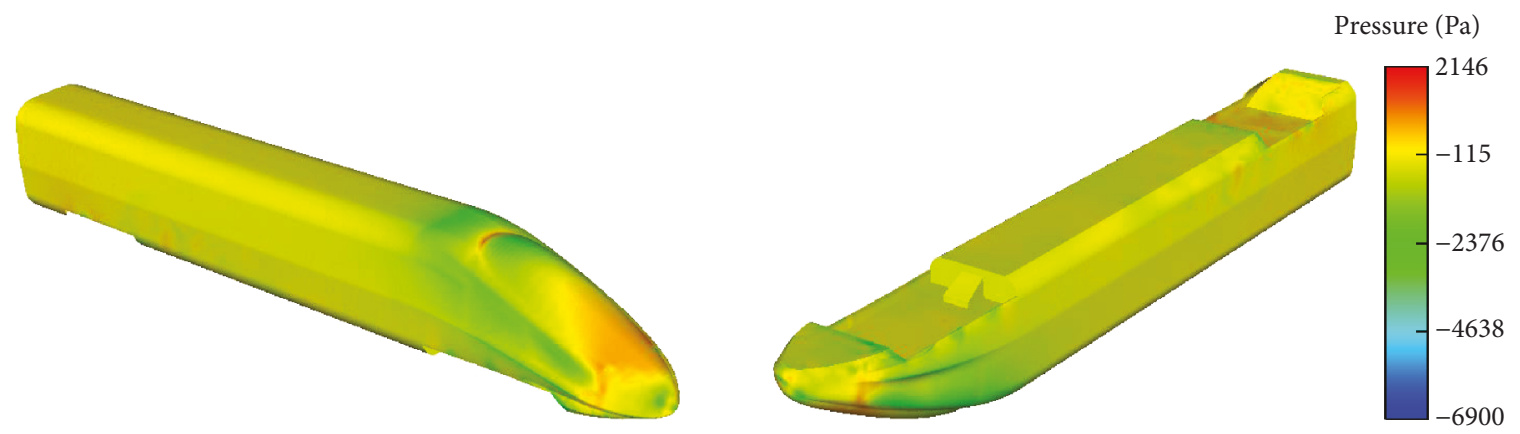

(c) Tail train

FIgURE 11: Pressure distribution on the surface of bionic trains.

noise can form strong noise pollution along the line. In order to research noise characteristics of the bionic train in farfield, 76 noise monitoring points were uniformly arranged along the longitudinal direction (X direction) of the train at positions which were $3.5 \mathrm{~m}$ higher above the track and $25 \mathrm{~m}$ away from the track according to international standards for testing noise of bionic trains ISO3095-2005 [38], wherein the distance between adjacent longitudinal monitoring points was $1 \mathrm{~m}$. At positions which were $3.5 \mathrm{~m}$ higher above the track and $7.5 \mathrm{~m}$ away from the track center, 8 noise monitoring points were arranged along the longitudinal direction of the bionic train, wherein 1 noise monitoring point was arranged at the head nose tip, the first-end bogie, the second-end bogie of the bionic head train, the first-end bogie of the bionic mid train, the second-end bogie of the bionic mid train, the second-end bogie of the bionic tail train, the first-end bogie of the bionic tail train, and the tail nose tip (number of monitoring points: y11, y12, y13, y14, y15, y16, $\mathrm{y} 17$, and $\mathrm{y} 18)$. At positions which were $1.2 \mathrm{~m}$ higher above the track and $7.5 \mathrm{~m}$ away from the center line of the track, 8 noise monitoring points were arranged along the longitudinal direction of the train, wherein 1 noise monitoring point was arranged at the head nose tip of the bionic train, the first-end bogie of the bionic head train, the second-end bogie of the bionic head train, the first-end bogie of the bionic mid train, the second end bogie of the bionic mid train, the second-end bogie of the bionic tail train, the firstend bogie of the bionic tail train, and the tail nose tip of the bionic train (number of monitoring points: y21, y22, $y 23, y 24, y 25, y 26, y 27$, and y28). Layout of noise bearing 


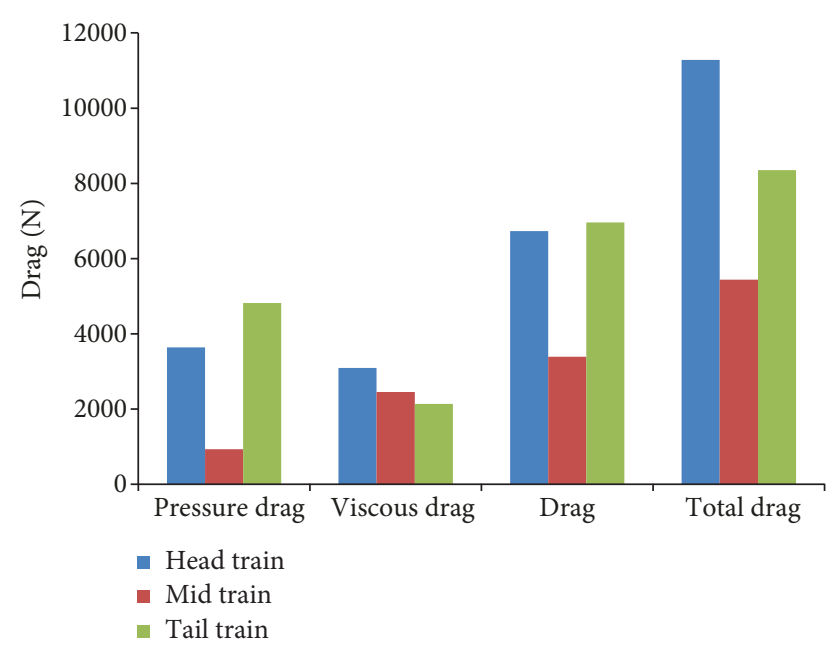

Figure 12: Aerodynamic drag of bionic model of high-speed trains.

points of the bionic train and number of noise bearing points are shown in Figure 13.

5.2. Distribution of Far-Field Noises for Bionic Trains. Figure 14 shows an A-weighting sound pressure level curve of longitudinal monitoring points during running of the bionic train model under $350 \mathrm{~km} / \mathrm{h}$, wherein the monitoring points were $25 \mathrm{~m}$ away from the track center line and $3.5 \mathrm{~m}$ higher above the track face.

It is shown in Figure 14 that distribution of longitudinal aerodynamic noise pressure levels of the high-speed train tended to decrease, wherein the noise bearing point in the first-end bogie area of the head train had the largest sound pressure level which reached the maximum value. Total sound pressure levels of the second-end bogie area of the head train, the first-end bogie area of the mid train, the second-end bogie area of the mid train, the second-end bogie area of the tail train, and the first-end bogie area of the tail train reached local maximum values. When the nose tip of the head train conducted transition to $x=7 \mathrm{~m}$, the noise level in far-field increased rapidly with the maximum increment of $4.9 \mathrm{~dB}(\mathrm{~A})$; after that, noise pressure levels of the whole train gradually decreased, while when the nose tip of the head train made transition to $x=7 \mathrm{~m}$, the far-field noise pressure level reached the maximum value at noise monitoring points of the whole train, namely, $88.4 \mathrm{~dB}(\mathrm{~A})$; when $x=11 \mathrm{~m}$, the far-field noise pressure level reached a large value of the noise monitoring point of the whole train, namely, $88.1 \mathrm{~dB}(\mathrm{~A})$; at streamline parts of the tail train, the noise pressure level got attenuated rapidly with the maximum attenuation value of $8.9 \mathrm{~dB}(\mathrm{~A})$. The total noise pressure levels reached locally large values near the second-end bogie of the head train, the first-end bogie of the mid train, the second-end bogie of the mid train, the second-end bogie, and the first-end bogie of the bionic tail train.

Figure 15 shows a comparative distribution diagram of A-weighting sound pressure levels of longitudinal monitoring points along the longitudinal direction of the train during running of the bionic model under different speeds $(350 \mathrm{~km} /$ $\mathrm{h}$ and $600 \mathrm{~km} / \mathrm{h}$ ), wherein noise bearing points were $25 \mathrm{~m}$ away from the track center line and $3.5 \mathrm{~m}$ higher above the track face.

It is shown in Figure 15 that noise levels of longitudinal noise bearing points increased significantly with the increase of train running speed. When the high-speed train ran at $600 \mathrm{~km} / \mathrm{h}$, its maximum noise level at the longitudinal noise bearing points was $99.7 \mathrm{~dB}(\mathrm{~A})$ with the average sound pressure level of $96.6 \mathrm{~dB}(\mathrm{~A})$; when the running speed increased from $350 \mathrm{~km} / \mathrm{h}$ to $600 \mathrm{~km} / \mathrm{h}$, the maximum noise level increased by $11.3 \mathrm{~dB}(\mathrm{~A})$, while the average sound pressure level increased by $11.6 \mathrm{~dB}$ (A). Meanwhile, it is shown in Figure 15 that, when the bionic model ran at different speeds, the total sound pressure levels of it at the first-end bogie of the head train, the second-end bogie of the head train, the firstend bogie of the mid train, the second-end bogie of the mid train, the second-end bogie of the tail train, and the first-end bogie area of the tail train reached locally maximum values.

Figure 16 shows the distribution of A-weighting sound pressure levels at 8 noise points which were arranged along the longitudinal direction, at positions which were $3.5 \mathrm{~m}$ higher above the track and $7.5 \mathrm{~m}$ away from the track center (number of noise bearing points: y11, y12, y13, y14, y15, y16, y17, and y18). It is shown in Figure 16 that A-weighting noise levels at the head nose tip of the bionic train, the first-end bogie of the head train, the second-end bogie of the head train, the first-end bogie of the mid train, the second-end bogie of the mid train, the second-end bogie of the tail train, the first-end bogie of the tail train, and the nose tip of the tail train were $87.7 \mathrm{~dB}(\mathrm{~A}), 92.9 \mathrm{~dB}(\mathrm{~A}), 89.8 \mathrm{~dB}(\mathrm{~A}), 90.5 \mathrm{~dB}(\mathrm{~A})$, $88.8 \mathrm{~dB}(\mathrm{~A}), 87.6 \mathrm{~dB}(\mathrm{~A}), 86.6 \mathrm{~dB}(\mathrm{~A})$, and $81.7 \mathrm{~dB}(\mathrm{~A})$. Increased amplitudes were $5.2 \mathrm{~dB}(\mathrm{~A}),-3.1 \mathrm{~dB}(\mathrm{~A}), 0.7 \mathrm{~dB}$ $(\mathrm{A}),-1.7 \mathrm{~dB}(\mathrm{~A}),-1.2 \mathrm{~dB}(\mathrm{~A}),-1.0 \mathrm{~dB}(\mathrm{~A})$, and $-4.9 \mathrm{~dB}(\mathrm{~A})$. The sound pressure level of the noise monitoring point $y 12$ near the first-end bogie of the bionic head train reached the maximum value of $92.9 \mathrm{~dB}(\mathrm{~A})$.

Figure 17 shows the distribution of A-weighting noise levels of 8 noise points which were arranged along the longitudinal direction and located at positions $1.2 \mathrm{~m}$ higher above the track and $7.5 \mathrm{~m}$ away from the track center line (number of monitoring points of noise bearing points: $y 21, y 22, y 23$, $y 24, y 25, y 26, y 27$, and y28). It is shown in Figure 16 that A-weighting noise levels at the head nose tip of the bionic train, the first-end bogie of the bionic head train, the second-end bogie of the bionic head train, the first-end bogie of the mid train, the second-end bogie of the mid train, the second-end bogie of the tail train, the first-end bogie of the tail train, and the nose tip of the tail train were $88.4 \mathrm{~dB}(\mathrm{~A})$, $95.1 \mathrm{~dB}(\mathrm{~A}), 92.2 \mathrm{~dB}(\mathrm{~A}), 92.3 \mathrm{~dB}(\mathrm{~A}), 89.6 \mathrm{~dB}(\mathrm{~A}), 90.1 \mathrm{~dB}$ (A), $89.5 \mathrm{~dB}(\mathrm{~A})$, and $82.4 \mathrm{~dB}(\mathrm{~A})$. Increased amplitudes were $6.7 \mathrm{~dB}(\mathrm{~A}),-2.9 \mathrm{~dB}(\mathrm{~A}), 0.1 \mathrm{~dB}(\mathrm{~A}),-2.7 \mathrm{~dB}(\mathrm{~A})$, $0.5 \mathrm{~dB}(\mathrm{~A}),-0.6 \mathrm{~dB}(\mathrm{~A})$, and $-7.1 \mathrm{~dB}(\mathrm{~A})$. The sound pressure level at the noise monitoring point y22 near the firstend bogie of the bionic head train reached the maximum value of $95.1 \mathrm{~dB}(\mathrm{~A})$.

Figure 18 shows a comparative diagram of A-weighting sound pressure levels of 16 noise bearing points which were arranged along the longitudinal direction of the train and located at positions $1.2 \mathrm{~m}$ and $3.5 \mathrm{~m}$ higher above the track and 7.5 away from the track center. Through comparison 


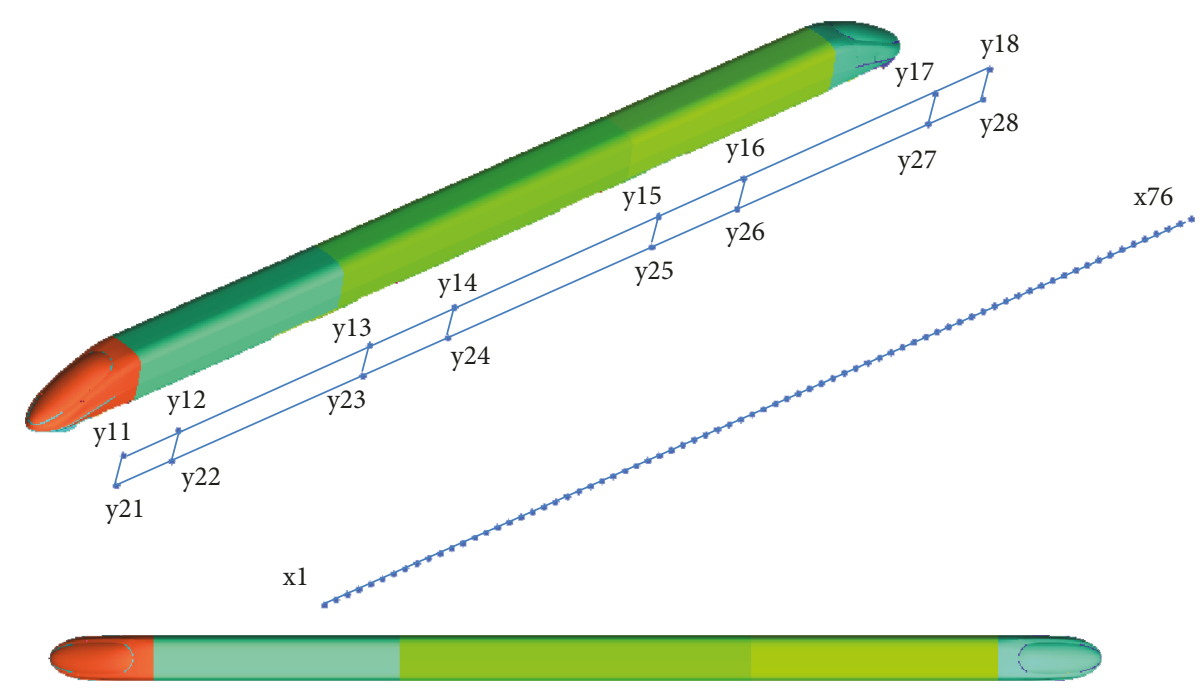

FIGURE 13: Distribution of noise points of bionic trains in far-field.

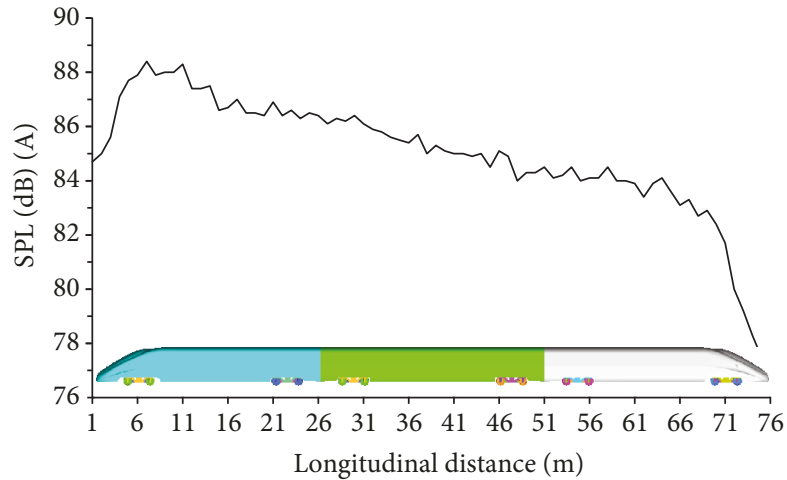

Figure 14: Distribution of noise levels of longitudinal noise bearing points.

of Figure 18, we can find that the sound pressure levels of noise bearing points which were $1.2 \mathrm{~m}$ higher were larger than those of the noise bearing points which were $3.5 \mathrm{~m}$ higher. Obviously, sound pressure levels of the noise bearing points closer to the ground were larger. Sound pressure levels of $1.2 \mathrm{~m}$ noise bearing points located at the head nose tip of the bionic train, the first-end bogie of the head train, the second-end bogie of the head train, the first-end bogie of the mid train, the second-end bogie of the mid train, the second-end bogie of the tail train, the first-end bogie of the tail train, and the nose tip of the tail train were $0.7 \mathrm{~dB}(\mathrm{~A}), 2.2 \mathrm{~dB}(\mathrm{~A}), 2.4 \mathrm{~dB}(\mathrm{~A}), 1.8 \mathrm{~dB}(\mathrm{~A})$, $0.8 \mathrm{~dB}(\mathrm{~A}), 2.5 \mathrm{~dB}(\mathrm{~A}), 2.9 \mathrm{~dB}(\mathrm{~A})$, and $0.7 \mathrm{~dB}(\mathrm{~A})$ larger than those of $3.5 \mathrm{~m}$ noise bearing points. In conclusion,

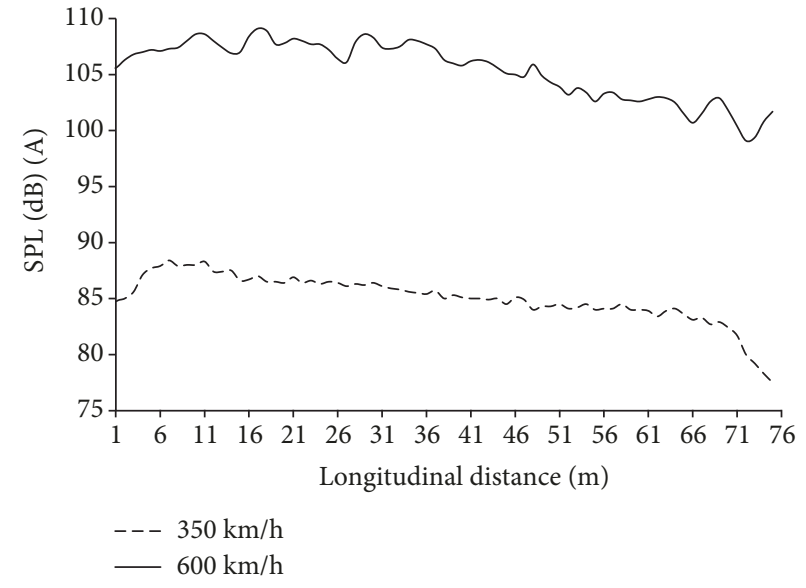

FIgURE 15: Comparison of sound pressure levels at longitudinal points with different speeds.

during testing noise of the bionic train, noise monitoring points should be arranged at the $y 2$ cross section, namely, at the first-end bogie of the head train.

Figure 19 shows a 1/3 octave comparison diagram of the bionic high-speed train at the monitoring point $\mathrm{x} 7$ (position with the maximum longitudinal sound pressure level). It is shown in Figure 19 that the noise of the bionic train was a wide frequency spectrum in far-field, wherein its energy was mainly concentrated within $630 \mathrm{~Hz} 3150 \mathrm{~Hz}$. With the increase of train running speed, the far-field aerodynamic noise energy moved to high frequencies. 


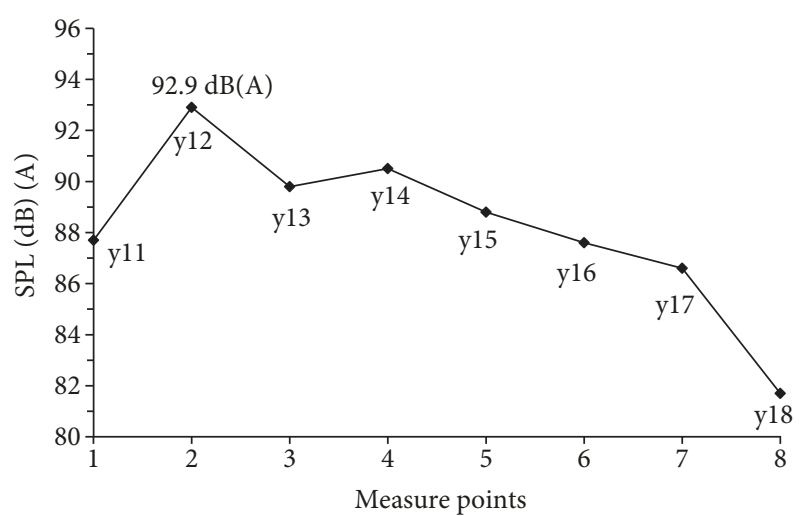

FIGURE 16: Distribution of noise levels of noise points which are $7.5 \mathrm{~m}$ far and $3.5 \mathrm{~m}$ high.

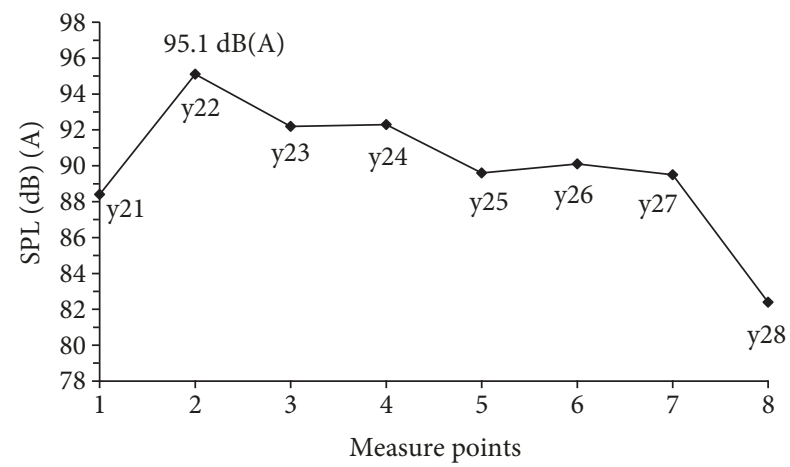

FIGURE 17: Noise levels of noise points which are $7.5 \mathrm{~m}$ far and $1.2 \mathrm{~m}$ high.

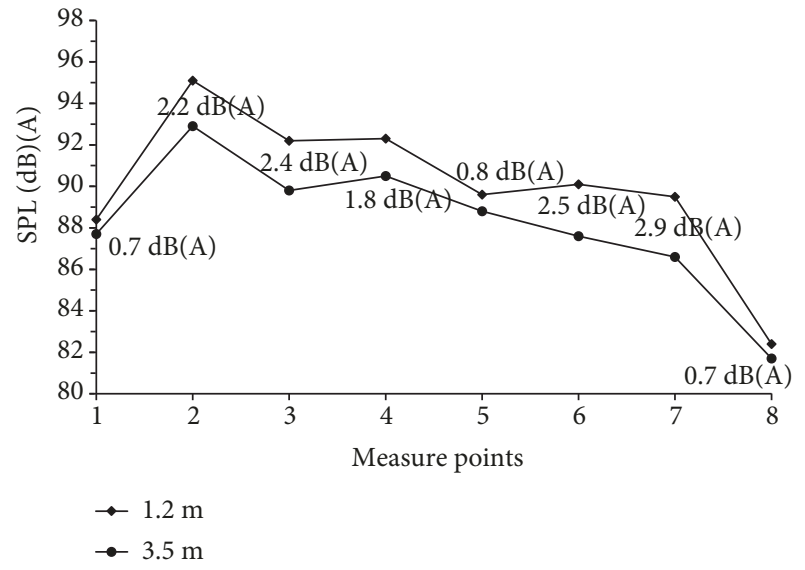

FIGURE 18: Comparison of sound pressure levels of monitoring points $7.5 \mathrm{~m}$ far.

\section{Conclusions}

With the continuous development of high-speed trains and the increase of running speeds, the aerodynamic problem of trains has become increasingly significant. Appearance of a train is closely associated with aerodynamic drag and aerodynamic noise of train running. In the paper, a bionic train model was established by CAD software. Through simulation

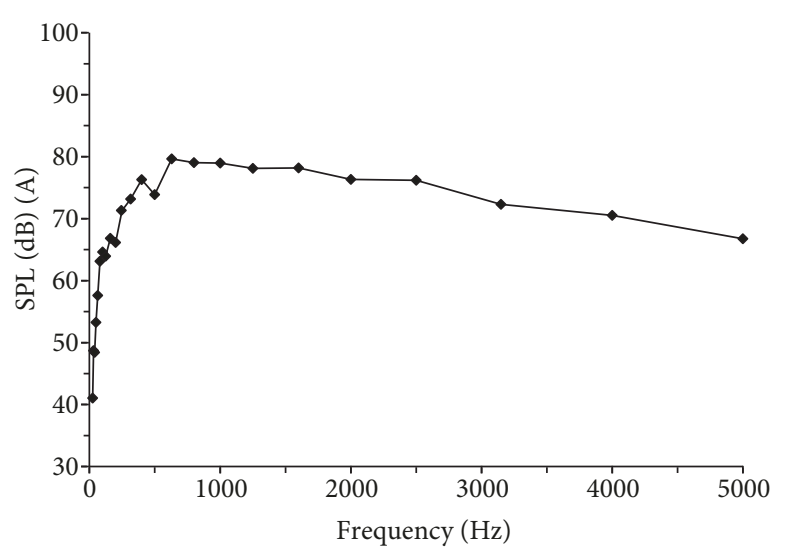

(a) $350 \mathrm{~km} / \mathrm{h}$

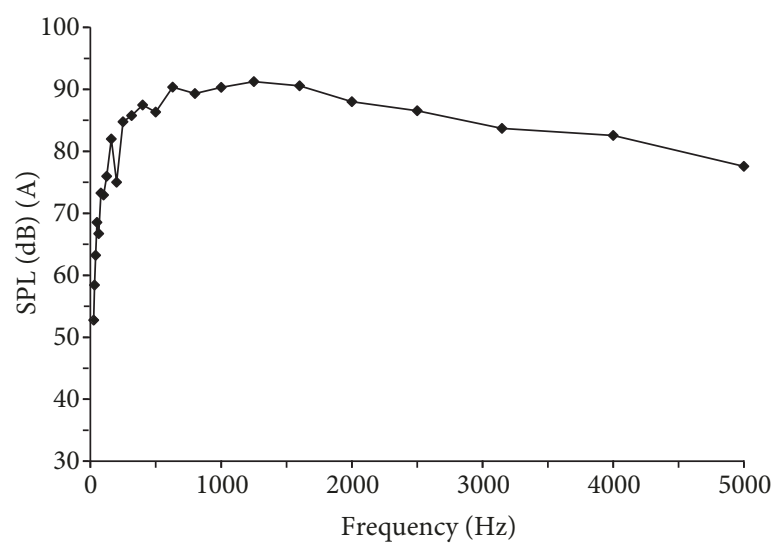

(b) $600 \mathrm{~km} / \mathrm{h}$

FIGURE 19: Comparison of sound pressure levels under 1/3 octave.

with the FLUENT and numerical simulation, aerodynamic drag reduction effect of the bionic train and influences of aerodynamic noise on the train were analyzed. The following conclusions are obtained:

(1) One animal with the high speed in the nature was selected. Characteristic control lines were extracted. Design requirements such as high-speed train limits were considered. CAD software was used to establish a bionic geometric model and a computation model of the high-speed train. Correctness of the model was verified. The CFD software was used to compute aerodynamic performance and aerodynamic noise characteristics during open-line running of the bionic design train. As analyzed from the perspective of drag reduction, drag of the bionic design head type was smaller than that of the CRH train; in comparison with the $\mathrm{CRH}$ train, the head train drag of the bionic train model was reduced by $2.21 \%$, and the whole-train drag was reduced by $3.53 \%$. Drag reduction effect was obvious. This result indicates that the bionic design head type has superiority in drag reduction.

(2) Sources of the bionic train are mainly located at positions with easy airflow separation and violent 
turbulence motion. Large turbulence energy exists in bogie areas and mainly exists at the leeward side of bogie area. Obviously, the bogie area is the major source area of the bionic train.

(3) Noise of the bionic train model is a wide-frequency spectrum in far-field, belonging to broadband noise. Energies are concentrated within $613 \mathrm{~Hz} 3150 \mathrm{~Hz}$.

(4) When the high-speed train ran at $350 \mathrm{~km} / \mathrm{h}$, through comparative analysis of total noise levels at observed points of the high-speed train, it is found that the maximum noise level existed at the $\mathrm{x} 7$ noise point which was $25 \mathrm{~m}$ away from the head train nose tip, with the maximum value of $88.4 \mathrm{~dB}(\mathrm{~A})$. Hence, in the subsequent experimental test, aerodynamic noise points should be arranged at this position as much as possible.

(5) When the bionic train ran at $600 \mathrm{~km} / \mathrm{h}$, the maximum noise level at the longitudinal noise bearing point was $99.7 \mathrm{~dB}(\mathrm{~A})$, and the average noise level was $96.6 \mathrm{~dB}(\mathrm{~A})$. When the running speed increased from $350 \mathrm{~km} / \mathrm{h}$ to $600 \mathrm{~km} / \mathrm{h}$, the maximum noise level increased by $11.3 \mathrm{~dB}(\mathrm{~A})$ and the average noise level increased by $11.6 \mathrm{~dB}(\mathrm{~A})$.

(6) Computation results of aerodynamic noise at the monitoring point which is $7.5 \mathrm{~m}$ away from the rail center show that the maximum aerodynamic noise level is at the first-end bogie part of the head train, while the noise level was larger at the position closer to the ground. It is suggested that noise bearing points shall be arranged at the first-end bogie of the head train and at positions closer to the ground in subsequent experiments.

\section{Data Availability}

The data used to support the findings of this study are available from the corresponding author upon request.

\section{Conflicts of Interest}

The authors declare that they have no conflicts of interest.

\section{Acknowledgments}

This work is supported by National Natural Science Foundation of China (Grant no. 51667017) and Key Research Projects of Tibet Autonomous Region for Innovation and Entrepreneur (Grant no. Z2016D01G01/01).

\section{References}

[1] W. B. Qi, Bionic Design in the Head Type and Lights of HighSpeed Trains, Southwest Jiaotong University, 2012.

[2] Z. Zhang and D. Zhou, "Wind tunnel experiment on aerodynamic characteristic of streamline head of high speed train with different head shapes," Journal of Central South
University (Science and Technology), vol. 44, no. 6, pp. 26032608, 2013.

[3] L. Q. Ren and Y. H. Liang, "Preliminary studies on the basic factors of bionics," Science China Technological Sciences, vol. 57, no. 3, pp. 520-530, 2014.

[4] B. T. Rutjens, J. Van Der Pligt, and F. Van Harreveld, "Deus or Darwin: randomness and belief in theories about the origin of life," Journal of Experimental Social Psychology, vol. 46, no. 6, pp. 1078-1080, 2010.

[5] L. Zhao, J. Ma, W. Chen, and H. Guo, "Lightweight design and verification of gantry machining center crossbeam based on structural bionics," Journal of Bionic Engineering, vol. 8, no. 2, pp. 201-206, 2011.

[6] S. A. Combes and T. L. Daniel, "Flexural stiffness in insect wings I. Scaling and the influence of wing venation," Journal of Experimental Biology, vol. 206, no. 17, pp. 2979-2987, 2003.

[7] S. A. Combes and T. L. Daniel, "Flexural stiffness in insect wings II. Spatial distribution and dynamic wing bending," Journal of Experimental Biology, vol. 206, no. 17, pp. 29892997, 2003.

[8] S. A. Combes and T. L. Daniel, "Into thin air: contributions of aerodynamic and inertial-elastic forces to wing bending in the hawkmoth Manduca sexta," Journal of Experimental Biology, vol. 206, no. 17, pp. 2999-3006, 2003.

[9] J. R. Usherwood and C. P. Ellington, "The aerodynamics of revolving wings I. Model hawkmoth wings," Journal of Experimental Biology, vol. 205, no. 11, pp. 1547-1564, 2002.

[10] Q. V. Nguyen, H. C. Park, N. S. Goo, and D. Byun, “Aerodynamic force generation of an insect-inspired flapper actuated by a compressed unimorph actuator," Science Bulletin, vol. 54, no. 16, pp. 2871-2879, 2009.

[11] H. Chen, X. H. Lin, Z. Cheng, and Q. W. Wang, "Aerodynamic performance of bionic foils based on trailing edge of pigeon," Energy Research and Management, vol. 28, no. 4, pp. 37-39, 2011.

[12] L. Shi, C. C. Zhang, J. Wang, Y. H. Wang, X.-p. Zhang, and L.-q. Ren, "Reduction of aerodynamic noise from NACA0018 airfoil model using bionic methods," Journal of Jilin University (Engineering and Technology Edition), vol. 41, no. 6, pp. 664668, 2011.

[13] P. Zhang, B. W. Song, and X. X. Du, "Numerical calculation of bionic flapping wing UUV's hydrodynamics," Computer Simulation, vol. 30, no. 1, pp. 397-400, 2013.

[14] G. Wang, D. Y. Zhang, and H. W. Chen, "The development of aircraft anti-icing-from traditional to bionic," Industrial Technology Innovation, vol. 1, no. 2, pp. 241-250, 2014.

[15] B. G. Tong, M. Sun, and X. Z. Yin, "A brief review on domestic research developments in biofluiddynamics of animal flying and swimming," Chinese Journal of Nature, vol. 27, no. 4, pp. 191-198, 2005.

[16] B. G. Tong and X. Y. Lu, "A review on biomechanics of animal flight and swimming," Advances in Mechanics, vol. 34, no. 1, pp. 1-8, 2004.

[17] X. Y. Jin, Y. Xu, L. Q. Zhang, and J. P. Yan, "Study on movement consistency of insects flying and fish swimming," Machine Design and Research, vol. 28, no. 6, pp. 4-6, 2012.

[18] C. Bouchard, A. Aoussat, and R. Duchamp, "Role of sketching in conceptual design of car styling," Journal of Design Research, vol. 5, no. 1, p. 116, 2006.

[19] L. M. Tian, Z. Shang, G. L. Hu, and N. Li, "Numerical simulation of the lift and drag characteristics of passenger car 
based on morphological bionics," Journal of Jilin University (Engineering and Technology Edition), vol. 44, no. 5, pp. 12831289, 2014.

[20] X. Song, G. Zhang, Y. Wang, and S. G. Hu, "Use of bionic inspired surfaces for aerodynamic drag reduction on motor vehicle body panels," Journal of Zhejiang University-Science A, vol. 12, no. 7, pp. 543-551, 2011.

[21] J. Lee and J. Kim, "Approximate optimization of high-speed train nose shape for reducing micropressure wave," Structural and Multidisciplinary Optimization, vol. 35, no. 1, pp. 79-87, 2008.

[22] K. Hargroves and M. Smith, "Innovation inspired by nature: biomimicry,” Ecos, vol. 2006, no. 129, pp. 27-29, 2006.

[23] J. Du, M. Gong, A. Q. Tian, N. Gao, and Z. W. Li, "Study on the drag reduction of the high-speed train based on the bionic non-smooth riblets," Journal of Railway Science and Engineering, vol. 11, no. 5, pp. 70-76, 2014.

[24] J. G. Wang, S. H. Chen, and Q. J. Wang, "Effect of bionic rhombic surface texture on friction noise of high-speed train," Journal of Traffic and Transportation Engineering, vol. 14, no. 1, pp. 43-48, 2014.

[25] J. Wang, S. Chen, and Q. Wang, "Bionic design of Koch snowflake surface texture and its effects on air frictional noise of high speed train," Journal of Mechanical Engineering, vol. 50, no. 7, pp. 78-83, 2014.

[26] B. C. Xu, Y. Zhang, and Y. Li, "The analysis on modeling design characteristics of Chinese traditional railway passenger car," Journal of Machine Design, vol. 35, no. 4, pp. 103-105, 2013.

[27] Z. R. Xiang, B. C. Xu, and J. Y. Zhi, "Review and prospect of research of industrial design of high-speed train in China," Journal of the China Railway Society, vol. 30, no. 12, pp. 9$18,2013$.

[28] Q. Yi, R. X. Mao, and S. W. Zhang, "Applications of bionic shaping design in industrial design of railway vehicles," Electric Locomotives \& Mass Transit Vehicles, vol. 35, no. 3, pp. 58-62, 2012.

[29] W. Wang and Z. Wang, "Analysis of the appearance design of high speed train in South Korea," Packaging Engineering, vol. 35 , no. 14 , pp. 28-31, 2014.

[30] M. Suzuki, K. Tanemoto, and T. Maeda, "Aerodynamic characteristics of train/vehicles under cross winds," Journal of Wind Engineering and Industrial Aerodynamics, vol. 91, no. 1-2, pp. 209-218, 2003.

[31] B. Greschner, F. Thiele, M. C. Jacob, and D. Casalino, "Prediction of sound generated by a rod-airfoil configuration using EASM DES and the generalised Lighthill/FW-H analogy," Computers \& Fluids, vol. 37, no. 4, pp. 402-413, 2008.

[32] A. A. Igci and M. E. Arici, "A comparative study of four lowReynolds-numberk-eturbulence models for periodic fully developed duct flow and heat transfer," Numerical Heat Transfer, Part B: Fundamentals, vol. 69, no. 3, pp. 234-248, 2016.

[33] S. Vijiapurapu and J. Cui, "Performance of turbulence models for flows through rough pipes," Applied Mathematical Modelling, vol. 34, no. 6, pp. 1458-1466, 2010.

[34] V. Yakhot and S. A. Orszag, "Renormalization group analysis of turbulence. I. Basic theory," Journal of Scientific Computing, vol. 1, no. 1, pp. 3-51, 1986.

[35] E. J. Kansa, "Multiquadrics-a scattered data approximation scheme with applications to computational fluid-dynamics-I surface approximations and partial derivative estimates,"
Computers \& Mathematics with Applications, vol. 19, no. 8-9, pp. 127-145, 1990.

[36] B. Fan, The Research of the Bionic Non-Smooth Structure for the Cavity Aerodynamic Noise Reduction, Jilin University, 2015.

[37] Y. L. Wan, Dynamics and Fatigue Life of Three-Dimensional Structure of Dragonfly Wing, Jilin University, 2010.

[38] EN ISO 3095, "Railway application-acoustics measurement of noise emitted by railbound vehicle," 2005. 


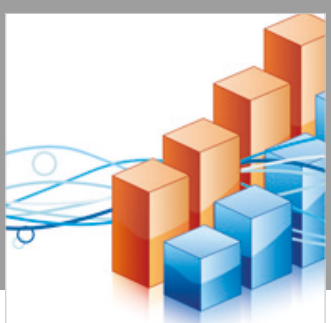

Advances in

Operations Research

\section{-n-m}
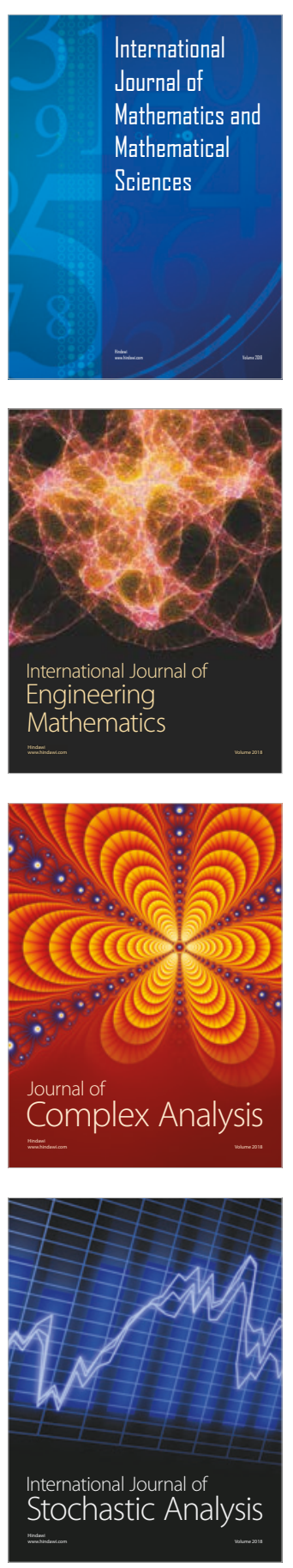
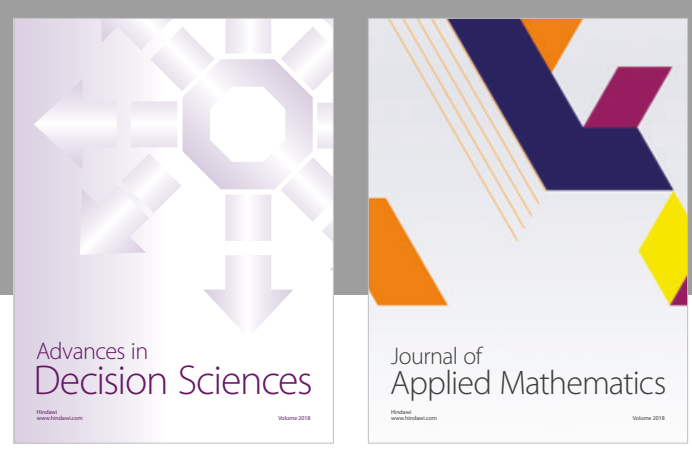

Journal of

Applied Mathematics
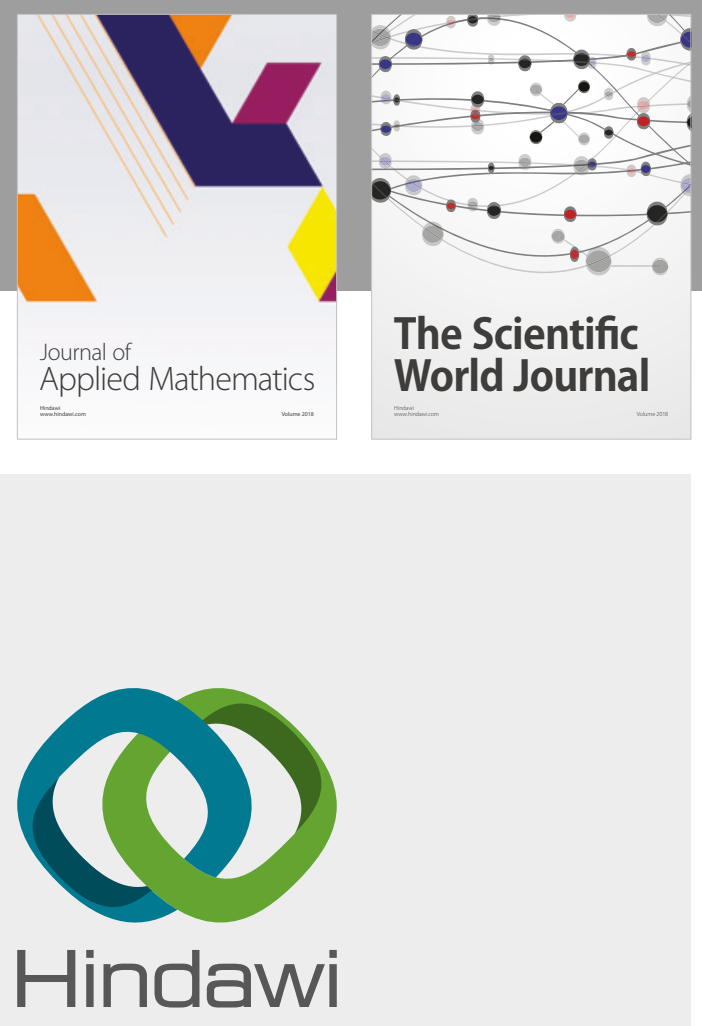

Submit your manuscripts at

www.hindawi.com

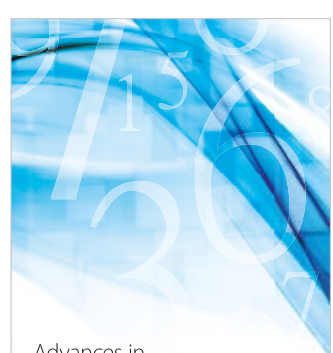

Advances in
Numerical Analysis
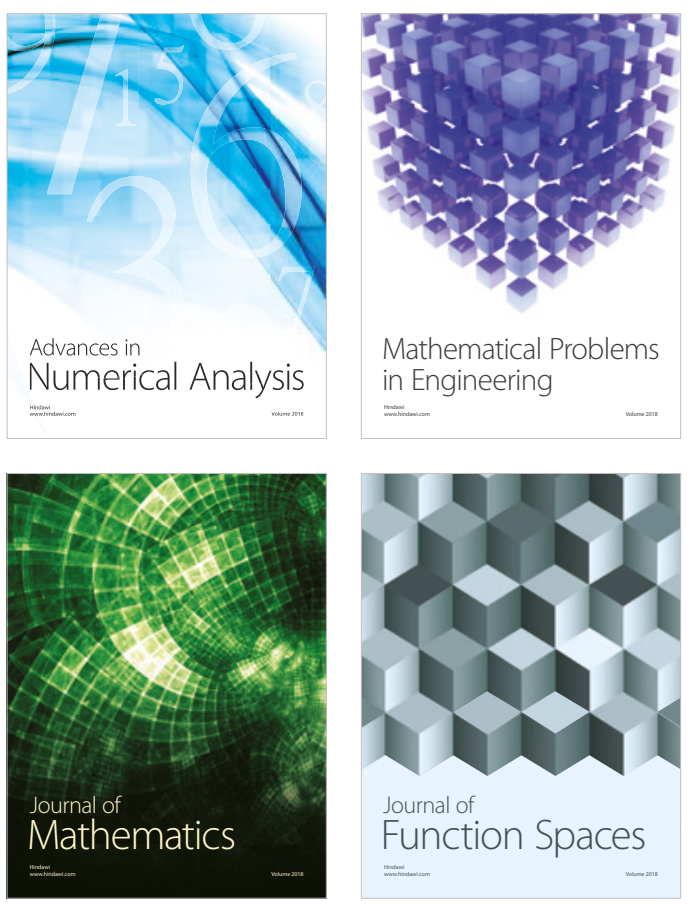

Mathematical Problems in Engineering

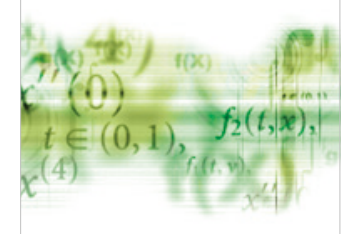

International Journal of

Differential Equations

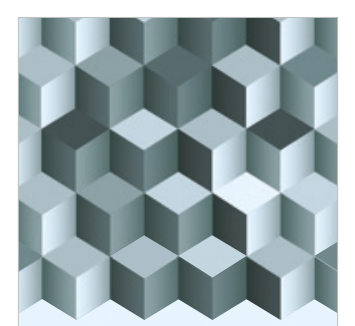

Journal of

Function Spaces
The Scientific

World Journal

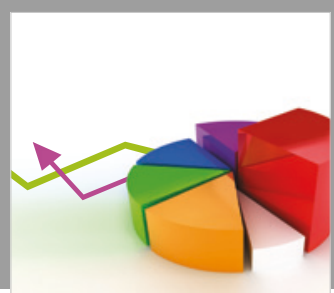

Journal of

Probability and Statistics
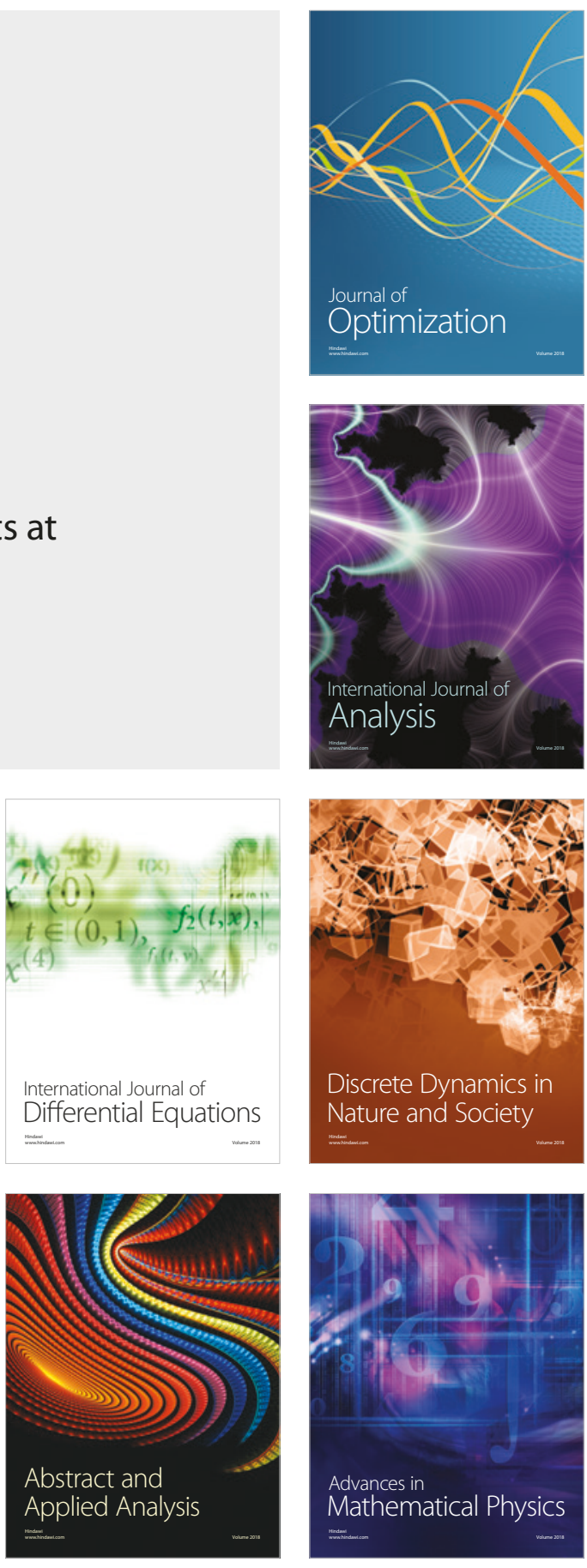